\title{
EL NACIONALISMO VASCO EN EL MARCO CONSTITUCIONAL DE LA II REPÚBLICA ESPAÑOLA (1931-1936)
}

\section{BASQUE NATIONALISM WITHIN THE CONSTITUTIONAL FRAMEWORK OF THE SECOND SPANISH REPUBLIC (1931- 1936)}

\author{
Gabriel Moreno González \\ Universitat de València \\ Gabriel.Moreno-Gonzalez@uv.es
}

Recibido: junio de 2018

Aceptado: julio de 2018

Palabras clave: Nacionalismo Vasco, Segunda República Española, Estatuto de Autonomía, Guerra Civil Española

Key words: Basque Nationalism, Second Spanish Republic, Statute of Autonomy, Spanish Civil War

Resumen: el presente artículo aborda el recorrido del nacionalismo vasco durante la II República Española y su adecuación al nuevo marco constitucional. En él se explora la centralidad que el PNV tuvo desde el inicio y los recelos que despertó su proyecto hegemónico en Euskadi desde las élites republicanas españolas, que lo consideraban abiertamente contrario a los valores, principios y objetivos de la Constitución de 1931.

Abstract: this article analyzes the life of Basque nationalism during the Second Spanish Republic and its adequation to the new constitutional framework. The author explores the centrality of the Basque Nationalist Party from the very beginning and its rejection by republican Spanish elites, who considered the project contrary to the values, principles and objetives of the 1931 Constitution.

\author{
¿Por qué no aspirar a una España que sea \\ armonía, donde hallen fecunda resonancia \\ todas las melodías peninsulares y en ella den su eco \\ emocionado como un corazón innumerable? ${ }^{1}$ \\ Ortega y Gasset
}

1. ORTEGA Y GASSET, J., Obras completas, Alianza-Revista de Occidente, Madrid, 1983, vol. VI, p. 219. 


\section{l.Introducción}

La complejidad que todo estudio de los nacionalismos comporta implica, cuanto menos, una no menor dificultad en cualquier aproximación, por breve que sea, a una de sus concreciones específicas. A la nación como Sursum corda salvífico se han asido ideologías y movimientos de toda naturaleza y condición para justificar fines injustificables, al tiempo que ha servido de base para las más sutiles creaciones y recreaciones artísticas. Así ilustra el historiador inglés Eric Hosbawn la complejidad a la que aducimos:

Supongamos que un día, después de una guerra nuclear, un historiador intergaláctico aterriza en un planeta muerto con el propósito de investigar la causa de la lejana y pequeña catástrofe que han registrado los sensores de su galaxia... Nuestro observador, después de estudiar un poco, sacará la conclusión de que los últimos dos siglos de historia humana del planeta Tierra son incomprensibles si no se entiende un poco el término "nación"... Este término parece expresar algo importante en los asuntos humanos. Pero, ¿exactamente qué? Ahí radica el misterio. ${ }^{2}$

¿Exactamente qué?...La eterna lucha dialógica entre antagonismos que subyace a la esencia de Europa a través de los diferentes periodos históricos nos ha enseñado que de la síntesis de los polos otrora enfrentados surgen nuevas ideas que colonizan las agitadas mentes europeas. ${ }^{3}$ Como si de una eclosión se tratara, el nacionalismo cultural hunde sus raíces

2. HOBSBAWN, E., Naciones y nacionalismo desde 1780, Ed. Crítica, Barcelona, 1995, p. 9.

3. MORIN, E., Pensar Europa. La metamorfosis de un continente, Gedisa, Barcelona, 2003. Para Morin, ésta constituye la esencia de Europa. en el romanticismo antitético a la visión racionalista ilustrada. La recuperación de lo perdido, de las esencias olvidadas, de las tradiciones y costumbres que, imperecederas como el espíritu de los pueblos, conforman las naciones, se convierte para la intelligentsia del viejo continente en un objetivo idealista y redentor. El volkgeist constituye el sustrato común de una nación cultural inmutable y apriorística, independiente de los Estados seculares y de sus correlatos, las naciones políticas.

Romanticismo y nacionalismo, nacionalismo y romanticismo, que ven cómo la industrialización y la centralización de una cultura homogénea, mediatizada y dominante, se abren paso a través de la modernidad. El rechazo a esta nueva realidad, la del Estado capitalista-industrial, donde impera, por necesidades funcionales, una misma visión de lo común-nacional, provoca que algunos de los grupos locales que no se ven identificados con esa nueva tendencia homogeneizadora impulsada desde el centro propicien el surgimiento de nacionalismos periféricos, contrarios a la modernidad y a sus consecuencias. ${ }^{4}$ Así, intentan crear estructuras de autogobierno que, utilizando los mismos medios e instrumentos del Estado central que aborrecen, Ileven a cabo una nueva homogeneización cultural, pero esta vez, desde los particularismos locales. La invención de costumbres y símbolos, la recuperación de lenguas relegadas al olvido o, incluso, la reivindicación de rasgos genéticos propios y unívocos, sirven a tal fin unificador desde lo local y frente a lo central.

Y es en este marco donde debemos encuadrar el nacimiento del nacionalismo

4. GELLNER, E., Naciones y nacionalismo, Alianza Universidad, Madrid, 2001, p. 101. 
vasco, de profundas raíces tradicionalistas e integristas, heredero del carlismo más radical y antiliberal. El odio a la modernidad industrializada, representada por lo español, y al modelo liberal de representación que acarrea, no muy amigo de la confesionalidad, es recogido con extrema animadversión por un carlista de la pequeña burguesía vizcaína: Sabino Arana Goiri.

Pocos movimientos deben tanto a una misma y única persona que el nacionalismo vasco a Sabino, hasta el punto que en determinados momentos el aranismo ha sido sinónimo de nacionalismo. El partido que él mismo fundó en 1895, el PNV, ha monopolizado buena parte de todo el nacionalismo vasco hasta bien entrada la segunda mitad del siglo XX, y constituye, a día de hoy, el segundo partido más antiguo de España, por detrás del PSOE.

Su recorrido a través de la primera mitad del siglo XX, en medio de una monarquía caciquil y una España poco dada a las aventuras territoriales, no estuvo exento de dificultades. Pero el PNV consiguió llegar hasta la II República conservando la esencia de su ideario, cercano, como veremos, a lo más reaccionario y tradicionalista que puede imaginarse.

Ver cómo se encuadró esta ideología con los nuevos tiempos en los que entraba España, cuál fueron sus tensiones con la República y cuáles sus objetivos políticos dentro del nuevo régimen, constituye el objeto de estudio del presente trabajo. Hemos dejado a un lado el turbio periodo de la Guerra Civil, donde el PNV y las provincias vascas consiguen ya su tan ansiado Estatuto. Nos centraremos, pues, en el análisis del nacionalismo vasco durante el periodo de paz de la II República, no sin antes llevar a cabo, como es de recibo, un breve recorrido por los antecedentes his- tóricos que lo precedieron ya que, como nos recordara D. Francisco Tomás y Valiente, "no hay dogmática sin historia. ${ }^{5}$

\section{La España liberal y los particularismo locales}

Es indudable que la Revolución liberal que comienza a principios del siglo XIX en Europa necesita de un nacionalismo unificador que legitime al nuevo Estado tras la desaparición de los fundamentos tradicionalistas, historicistas y religiosos que habían sustentado el Antiguo Régimen. Surge así un nacionalismo de tipo político, liberal o liberal-democrático, que tiene su fundamento en la lealtad al Estado y a la Nación, Nación que es ahora consciente de su autolegitimidad política como fundante y reproductora de aquél.

España no es pasiva a esta nueva realidad. Desde el liberalismo gaditano o, incluso, desde los pensadores ilustrados, se va tejiendo una compleja y diversa madeja de nacionalismo político que llega hasta la II República. Dos tradiciones, la liberal y la liberal-democrática española, tan olvidadas como injustamente tratadas. Dice D. Manuel Azaña:

Nosotros más o menos venimos a continuar cuanto ha sido en España el pensamiento independiente y libertad de espíritu... ¿Quién no ha percibido a lo largo de nuestra historia intelectual y moral la queja murmurante al margen de lo ortodoxo? Somos sus herederos. ${ }^{6}$

5. TOMÁS Y VALIENTE, Francisco, Obras completas, Centro de Estudios Políticos y Constitucionales (en adelante CEPC), Madrid, 1997, tomo III, p. 2.587.

6. AZAÑA, M., La velada de Benicarló, Edit. Castalia, Madrid, 1974, pp. 186 y 187. 
Y más profusamente:

Yo hablo de la tradición humanitaria y liberal española, porque esa tradición existe, aunque os la hayan querido ocultar desde niños maliciosamente. España no ha sido siempre un país inquisitorial, ni un país intolerante, ni un país fanatizado, ni un país atraillado a la locura. No ha sido siempre así, señores, y a lo largo de toda la historia de la España oficial, a lo largo de toda la historia de la España imperial, a lo largo del cortejo de dalmáticas y de armaduras y estandartes, que todavía se ostentan en los emblemas oficiales de España, a lo largo de toda esa teoría de triunfos o de derrotas, de opresiones o de victorias, de persecuciones o de evasiones del suelo nacional, paralelo a todo eso ha habido siempre durante siglos en España un arroyuelo murmurante de gentes descontentas, del cual arroyuelo nosotros venimos y nos hemos convertido en ancho río.?

Nacionalismo liberal español, tan bien sintetizado por Azaña, que se consolida ya durante el siglo XIX, a pesar de tener que combatir ideologías antiliberales propias de otras épocas, como el carlismo. El rechazo al pensamiento liberal y al proceso de secularización que conllevaba, provoca en España no solo tensiones políticas, sino también bélicas. Dicho rechazo convierte la conservación de los viejos Fueros de las provincias vascas y Navarra en núcleo de resistencia frente al centralismo liberalizador. La victoria de los liberales-cristinos en la Primera Guerra Carlista (1833-1839) conllevó la aprobación de la ley de 25 de octubre de 1839, auspiciada por el general Espartero y que venía a confirmar los Fueros al tiempo que introducía cláusulas

7. AZAÑA, M., Obras completas, Edit. Oasis, México, 1966, t. II, pp. 693 y 694. Se reproduce aquí una charla en la sociedad El Sitio, de Bilbao, que el 9 de abril de 1933 pronunció el que luego sería Presidente de la República. ambiguas para su derogación. La sublevación de las provincias vascongadas en 1841 contra el nuevo régimen progresista de Espartero y a favor de la restauración liberal-moderada de Isabel, provocó que el general decretara la abolición de los Fueros, que serían de nuevo restaurados a la vuelta de los moderados. En 1876, tras la victoria de Alfonso XII en la Tercera Guerra Carlista, los Fueros serían definitivamente abolidos en las provincias vascongadas, aun conservando cierto régimen de concierto económico.

Este hecho prepara el terreno para el surgimiento de un nacionalismo cultural y periférico de base romántica, fuerista y tradicionalista, enfrentado al nacionalismo liberal o liberal-democrático centralista y moderno. ${ }^{8}$ Sabino Arana, carlista convencido, será el que abandone el carácter nacional-español del carlismo para abanderar una nueva ideología nacionalista con la creación del antagonismo vasco-español. Conservando la esencia tradicionalista, integral católica y reaccionaria del carlismo, pero concentrándolo en una visión "vasquista," irá creando el andamiaje de un nuevo nacionalismo periférico. Lo español se asemeja a liberal, a moderno, a centralista, mientras que lo vasco es identificado con las esencias tradicionales e históricas de lo rural, lo campesino, lo puro y religioso. El liberalismo es visto como una imposición españolista que entra en el País Vasco a través de la abolición de los fueros, cuyo proceso comienza en 1839 tras la derrota en la Primera Guerra Carlista. ${ }^{9}$ Para Sabino, antes de esa fecha, los territorios históricos de

8. Para una visión de esta tradición española, vide. DE BLAS GUERRERO, A., Tradición republicana y nacionalismo español, Tecnos, Madrid, 1991.

9. Cfr. FERNÁNDEZ SEBASTIÁN, J., "Antecedentes: fuerismo, carlismo y nacioalismo", en 
las vascongadas y de Navarra disfrutaban de un régimen de independencia y libertad, donde la "etnia vasca" se desenvolvía dentro de su tradicional apego a las instituciones tradicionales y a la religión. ${ }^{10}$

Ya no estamos ante dos visiones de España, la tradicionalista del carlismo y la liberal, sino ante una nueva realidad nacionalista que hace frente a la misma idea de España. El nacionalismo vasco que surge a finales del XIX bajo la batuta de Arana es, además, un nacionalismo de tipo cultural exacerbado, sin atisbo alguno de liberal, de ese liberalismo que tanto odia. Por ello, parte de la base de elementos culturales (lengua, costumbres, tradiciones, etc) y hasta de elementos étnico-racistas (la raza vasca) como criterios diferenciadores del nacionalismo político-liberal representado por lo español. El nacionalismo cultural se desarrolla, pues, frente al otro, frente al que se considera sino enemigo, al menos diferente y antagonista. ${ }^{11}$

\section{El Partido Nacionalista Vasco}

Con estas ideas, Arana funda en 1895 el Partido Nacionalista Vasco, verdadero

Los nacionalistas: historia del nacionalismo vasco, 1876-1969, 1995, pp. 17-51.

10. Para un estudio del racismo en el primer nacionalismo vasco, puede verse QUIROGA FERNÁNDEZ DE SOTO, A., "Hermanos de sangre. Regenaracionismo, catolicismo y racismo en los nacionalismos españoles, catalanes y vascos (1890-1945)," en Joaquín Costa y la modernización de España, marzo, 2011.

11. MOLAS, I., "Los nacionalismos durante la II República. Una perspectiva comparada”, en BERAMENDI, J. G., y MÁIZ, R., (Comps.), Los nacionalismos en la España de la II República, Siglo XXI Editores, Madrid, 1991, p. 14 y ss. motor político y social que monopoliza el nacionalismo vasco hasta 1930 , cuando surge Acción Nacionalista Vasca (ANV). Durante esos más de 30 años, el PNV será el encargado de ir tejiendo y configurando el nacionalismo y la primigenia idea de nación vasca. Para ello, no dudará el utilizar medios artificiales y completamente inventados. Como nos recuerda Gellner de nuevo:

El nacionalismo engendra a las naciones, no a la inversa. No puede negarse que aprovecha-si bien de forma muy selectiva y a menudo transformándolas radicalmente- la multiplicidad de culturas, o riqueza cultural preexistente, heredada históricamente. Es posible que haga revivir lenguas muertas, que se inventen tradiciones y que se restauren esencias originales completamente ficticias. ${ }^{12}$

Labor creativa y recopilatoria que será impulsada por el PNV y por la Sociedad de Estudios Vascos (SEV), creada en 1918 por las Diputaciones Forales para desarrollar y consolidar la "cultura euskalduna." 13

A pesar de que en sus últimos años de vida, el pensamiento de Arana da un giro españolista y abandona la radicalidad de sus planteamientos nacionalistas, el PNV recogerá el legado e ideario de su primera etapa tras la muerte de su fundador (1903). El integrismo religioso-católico, el odio hacia el liberalismo y la modernidad, el antagonismo vasco/español asentado en criterios etnocéntricos y el tradicionalismo más exacerbado (incluido un machismo sin igual en la época), son

12. GELLNER, E., op. cit., p. 80.

13. Para un estudio concienzudo de los orígenes del nacionalismo vasco, puede verse CORCUERA J., Orígenes, ideología y organización del nacionalismo vasco (1876-1904), Siglo XXI, Madrid, 1979;: SOLOZABAL, El primer nacionalismo vasco, Tucar, Madrid, 1975. 
Ios elementos esenciales que defiende el PNV durante las tres primeras décadas de existencia, bajo la bandera, siempre, de un nacionalismo cultural separatista. ${ }^{14}$

Separatismo, sí, pero al mismo tiempo una defensa paradójica del autonomismo. Durante esta primera andadura, el PNV defenderá la creación de instituciones comunes de autogobierno dentro del Estado español, sin renunciar, eso sí, al ideal independentista. De hecho, ya en la temprana fecha de 1898 parece atenuarse el ansia independentista en la propia persona de Sabino, quien tras ser elegido diputado, plantea una especie de Mancomunidad para el País Vasco que integre a las 4 diputaciones (las tres vascongadas más Navarra) en una región dentro de España. ${ }^{15}$

Este dilema, autonomismo versus independentismo, recorre el PNV desde sus inicios hasta la actualidad, siendo teóricamente independentistas pero pragmáticamente autonomistas. Dependiendo de las situaciones históricas a las que se enfrentan, los nacionalistas vascos optarán por recalcar más una vertiente $u$ otra, pero sin renunciar nunca en la teoría y en las proclamaciones más retóricas y propagandísticas, a la independencia de lo que ellos llaman Euskal Herria. ${ }^{16}$

14. DE LA GRANJA, J. L., "El nacionalismo vasco entre la autonomía y la independencia," en BERAMENDI, J. G y MÁIZ R., Los nacionalismos en la España ....op. cit., p. 102

15. Para un análisis centrado en la obra de Arana, puede verse LARRONDE J. C., El nacionalismo vasco: su origen y su ideología en la obra de Sabino Arana-Goiri, Txertoa, San Sebastián, 1977.

16. CORCUERA, J., "Perspectiva del nacionalismo vasco. Integración y asimilación", en Revista Internacional de Sociología, enero-marco de 1983, no 45, p. 57.
No obstante los devaneos de Sabino con el autonomismo pro-españolista, ${ }^{17}$ siempre se tendrá como ideas puras del nacionalismo, el llamado aranismo, su primera etapa, la de radicalidad independentista etnocéntrica y antiliberal que propugna el restablecimiento de la libertad vasca a través de los Fueros derogados por la Monarquía centralista. Las tendencias más moderadas y autonomistas (Ilamadas eskalerriacas) en el seno del PNV durante los años 20, alternadas con los aranistas puros, provocarán la primera gran escisión ${ }^{18}$ en el nacionalismo vasco con la separación de Aberri, grupo radicalindependentista y de profunda raigambre aranista. ${ }^{19}$ Por su oposición a las negociaciones con las Cortes monárquicas que estaba llevando a cabo el sector más regionalista del PNV, deciden en 1921 escindirse y capitanear un nuevo radicalismo nacionalista que ve en el ejemplo irlandés la vía a seguir. ${ }^{20}$ Es la etapa de liderazgo del rico naviero y fuerista Ramón de la Sota, partidario del regionalismo y, en el fondo, él mismo liberal. ${ }^{21}$

Pero la tendencia aranista e independentista vuelve luego a tomar las riendas del

17. Llegó incluso a proponer la creación de una Liga de Vascos Españolistas.

18. En 1909 se había creado el Partido Republicano Nacionalista Vasco, de tendencia liberal y laica, opuesto al conservadurismo del PNV.

19. Para un estudio de las diversas ideologías que conviven dentro del PNV, vide ELORZA, A., Ideologías del nacionalismo vasco. 1876-1937, Aramburu, San Sebastián, 1978.

20. Landeta propone, en 1923, abandonar el aranismo y el objetivo último de la independencia, pero sus propuestas son obviadas en el seno del PNV.

21. Esta persona singular fundaría los Astilleros Euskalduna y llegaría a ser nombrado Sir por el Rey de Inglaterra. Una aproximación a su vida en TORRES VILLANUEVA, E., Ramón de la Sota: 1857-1936: un empresario vasco, LID, Madrid, 1998. 
PNV, que pasa a la clandestinidad, junto a toda su simbología, durante la Dictadura de Primo de Rivera. ${ }^{22}$ Estos años son, sin embargo, los del gran auge económico e industrial del País Vasco, que ve aumentada la producción industrial en más de un $200 \%$, Ilegando a sus ciudades decenas de miles de inmigrantes procedentes de Extremadura, Andalucía, Castilla, etc. ${ }^{23}$ La acción del PNV, desarrollada en la sombra, sigue fomentando la idea de una nación vasca, diferente de lo español, tanto étnica como culturalmente. Y ello choca, como no puede ser de otro modo, con la inmigración procedente del resto de España. ${ }^{24}$

Tras la caída de la Dictadura Aberri regresa al PNV, reunificándose el partido en la Asamblea de Bergara del 16 de noviembre de 1930. En dicha Asamblea, se vuelve al aranismo más puro, propugnándose la independencia y recalcando la naturaleza religiosa, integrista y tradicionalista de su ideario. El sector más moderado se separa y forma ANV (Manifiesto de San Andrés de 3 de noviembre de 1930), nuevo partido de corte liberal y aconfesional, pero nacionalista. Con contadas excepciones, el PNV representa la cuasi-totalidad del nacionalismo vasco en los inicios de la década de los 30 del pasado siglo,

22. Cfr. RAMOS LARRIBRA, C., "El nacionalismo vasco durante la dictadura de Primo de Rivera", en Letras de Deusto, vol. 15, no 31, 1985 pp. 137-170.

23. Cfr. HERNÁNDEZ MARCO, J. L., (Coord.), La industrialización del norte de España, Universidad del País Vasco, 1988, pp. 206-221.

24. El "antimaketismo" fue la ideología más radical dentro del nacionalismo vasco de corte racista y xenófobo respecto de los inmigrantes del resto de España. Vid., DE LA GRANJA SAINZ, J. L., "El antimaketismo: la visión de Sabino Arana sobre España y los españoles," en Norba. Revista de Historia, no 19, 2006, pp. 191-203. década que verá nacer en su seno, la II República Española.

\section{La implantación y base social del nacionalismo vasco en los años de la República}

El 14 de abril de 1931 los vivas a la República se suceden por las ciudades de España al conocerse los resultados de las elecciones municipales. El Rey, Alfonso XIII, tiene que abandonar el país rumbo al exilio, mientras en Madrid se constituye un Gobierno Provisional que proclama la II República y da inicio a un proceso constituyente para otorgar a España una Constitución.

El primer lugar donde se proclama la República es, precisamente, en el pueblo vasco de Éibar (Guipúzcoa), y el nuevo régimen es acogido, en general, con una profunda alegría y esperanza en Euskadi. Ahora bien, ¿cuál es la implantación real del nacionalismo vasco capitaneado por el PNV en aquella región de España a la llegada de la República? ¿Y durante ella?

En cierta medida, el proceso de expansión del nacionalismo resulta paradójico en cuanto va parejo al aumento de la industrialización del País Vasco. Como dice Jáuregui, "el nacionalismo va a adaptarse perfectamente a la nueva sociedad industrial, asentándose de modo firme en los núcleos urbanos e industriales." ${ }^{25} \mathrm{El}$ campo social en el que el nacionalismo se inserta y expande es el de la pequeña burguesía y trabajadores rurales del País Vasco. Este carácter interclasista es

25. JÁUREGUI GURUTZ, "Bases sociales en el nacionalismo vasco durante la II República", en BERAMENDI J. G., y MÁIZ R., Los nacionalismos en la España ...op. cit., p. 239. 
una más de las numerosas características sui generis del movimiento nacionalista. Aunque es un movimiento tradicionalista, no duda en crear su propio sindicato, Solidaridad de Obreros Vascos (SOV), en 1911. El SOV intentará abrirse paso en el movimiento obrero y en el proletariado de las grandes urbes vascas, pero será incapaz en sus inicios de desbancar al PSOE y a la UGT, que patrimonializan el sector obrero. Ello cristaliza el viejo antagonismo entre el socialismo y el nacionalismo, que perdura a lo largo de toda la República.

En los años previos a la República, la industrialización concentra su aumento en Guipúzcoa (aunque de manera dispersa) que llega tarde al proceso, y se consolida en Vizcaya, tradicional feudo del nacionalismo vasco (sobre todo Bilbao), donde nació y donde dio sus primeros pasos de la mano de Sabino. En ambas provincias, no obstante, el sector industrial supera el $40 \%$ de la ocupación laboral. A ello hemos de sumarle el alto grado de desarrollo económico y social que experimentan dichas zonas industriales durante la primera mitad del siglo XX, sin parangón en el resto de España. ¿Cómo, entonces, a pesar de su idiosincrasia, va penetrando el nacionalismo en la sociedad vasca?

El secreto se encuentra en la propia naturaleza del PNV, que no se considera a sí mismo como un partido político más, sino como un movimiento que integra todo el nacionalismo vasco, y aún más, la propia nación vasca. El aranismo que propugna implica el rechazo de lo español, la creación artificial de un antagonismo irreconciliable vasco/español como eje transversal e interclasista. Aunque durante la República dicho antagonismo se suaviza, "se mantiene en su intensidad y crudeza". ${ }^{26}$

26. Ibid., p. 243.
El PNV, sobre este eje, se autoconstituye como único representante legítimo de la comunidad vasca, desbordando así el esquema clásico de los partidos. Su táctica: penetrar en todo el tejido social vasco, sin distinción de clases, y sobre el único referente de la distinción amigo/enemigo, vasco/español.

De esta forma, e imitando los partidos de masas de la época, incluidos los fascistas, crea una serie de organizaciones y movimientos satélites a su estructura, que tienen por objeto la difusión del ideario del partido y la construcción de una comunidad nacional vasca frente a lo español. Así, se crean las Eusko Gaztedi, o Juventudes Vascas, las Emakume Abertzale Batza, sección femenina; la Universidad Social Obrera Vasca, organizaciones infantiles, centros sociales (euskal etxea), lugares de distensión (batzokis), decenas de asociaciones culturales, la Federación de Escuelas Vascas, la Federación de Maestros Vascos, clubes y prensa deportiva (Excelsior), etc...todos dependientes del PNV. Incluso se intentó, sin éxito, la creación de una patronal nacionalista vasca, Agrupación Vasca de Acción Social Cristiana (AVASC) de profundas raíces católicas. ${ }^{27}$ El PNV, como centro de todo este entramado, logra así entrar en todos los ámbitos de la sociedad vasca, en el político, en el sociolaboral y en el educativo-cultural.

La eficacia de esta táctica, innovadora para la praxis política de la época, junto a la transversalidad de su criterio de definición (el antagonismo vasco/español), le

27. Un listado completo puede encontrarse en la monumental monografía que José Luis de la Granja dedica al nacionalismo vasco durante la II República. DE LA GRANJA SAINZ, J. L., Nacionalismo y II República en el País Vasco, Siglo XXI, Madrid, 2008, pp. 32 y ss. 
dará grandes resultados. Desde el punto de vista número, su componente más importante es la clase trabajadora, tanto rural como urbana, siempre autóctona (a los inmigrantes se les veta la entrada, por ser españoles), y pronto se irá haciendo, poco a poco, con mayor presencia en el proletariado, desplazando a UGT y al PSOE, que quedarán relegados a la representación de los trabajadores inmigrantes. Para con los nacionalismos, el PSOE es mucho más intransigente que los republicanos (Azaña), pues ve cómo le pueden ir robando votos desde posiciones interclasistas que en nada ayudan a los trabajadores, que mutan su conciencia de clase por otra conciencia colectiva, la nacional o étnico-cultural, alejada del verdadero ideal socialista. De hecho, como apuntábamos, los miembros del PSOE/UGT, y los trabajadores inmigrantes, carecen siquiera de la capacidad de llegar a formar parte de la comunidad vasca, pues no cumplen con el parámetro etnocéntrico de lo autóctono. El problema se plantea cuando surgen dentro del PNV voces vascas discrepantes con su carácter conservador y tradicionalista, como ANV. Aquí, el criterio de lo étnico ya no puede imperar para rechazarla, de ahí el tímido desprecio del PNV a la nueva formación laica y republicana, que apenas tendrá , eso sí, incidencia en la vida política vasca durante el periodo republicano.

Con todo ello, durante los primeros años de la República, el PNV llega a alcanzar el $45 \%$ de los votos en Bilbao y superar el $25 \%$ en Guipúzcoa, en una tendencia progresiva al alza que no hará sino aumentar. ${ }^{28}$ Además del elemento interclasista y antagonista de la dicotomía vasco/español, el nacionalismo se sirve un cierto carácter social que tamiza de humana la industrialización. Al contrario de lo que pueda pare-

28. JAÚREGUI GURUTZ., op. cit., p. 241. cer en un primer momento, su rechazo al modelo liberal y su tradicionalismo no es óbice para aceptar la industrialización y la modernidad. Lo que repudian es el modelo político centralista-liberal que conlleva, y sus consecuencias. Es más, gran parte de los hombres insignes del nacionalismo vasco serán personas vinculadas con la industria, incluso grandes fortunas como Ramón de la Sota. ${ }^{29}$

Ese tamiz humano-social del proceso industrializador atraerá a buena parte de la clase obrera al SOV, que durante la República llega a los 40.000 afiliados, superando casi a la UGT. ${ }^{30}$ Tamiz humano que viene dado por el carácter católico de todo el movimiento nacionalista, influido en este punto por la doctrina social de la Iglesia (Encíclica Rerum Novarum, de León XIII). Adaptación vasca del catolicismo social español que llegará a estar teorizada a través del nacionalista Aitzol y su obra, La democracia en Euzkadi, de 1936. ${ }^{31} \mathrm{La}$ defensa de la doctrina social por parte del nacionalismo no conlleva, sin embargo, la adopción de ningún elemento socialista o revolucionario, sino todo lo contrario. El respeto por la propiedad privada y la armonía (cristiana) entre las distintas clases sociales se convierte en el paradigma a seguir. ${ }^{32}$ El SOV se aprovecha, además,

29. Así lo apunta CASTELL, L., Modernización y dinámica política en la sociedad guipuzcoana de la Restauración, 1876-1915, Siglo XXI, Madrid, 1987, pp. 338 y ss.

30. JAÚREGUI GURUTZ, op. cit., p. 249.

31. KORTAZAR URIARTE, J., "La literatura vasca y la creación de la Nación: ideas de José Aristimuño, "Aitzol” (1896-1936)", en ROMERO TOBAR, L., (Coord.), Literatura y nación: la emergencia de las literaturas nacionales, 2008, pp. 207-222.

32. DE PABLO, S., "Notas sobre la base social del nacionalismo vasco (1931-1936), en BERA- 
de la poca conciencia de clase de una sociedad rápidamente industrializada, sin tradición de lucha ni precedentes de conflictos sociales, arrancando el protagonismo a otras formaciones como el Partido Comunista Vasco, al que odia. El SOV se configura así como un sindicato sui generis, cuyas bases están compuestas por un proletariado autóctono nacionalista poco dado a revoluciones, sin conciencia de clase, y donde prima la contradicción vasco/español por encima de los antagonismos de clase. ${ }^{33}$

A pesar de ello, parte de las bases del SOV llegan a apoyar la huelga general revolucionaria de octubre del 34, en contra de la dirección del sindicato y del propio PNV, que no fue capaz de evitar un enfrentamiento entre los trabajadores nacionalistas y la patronal, también nacionalista, AVASC, sustentada principalmente por la Iglesia. ${ }^{34}$

Por otro lado, y como hemos visto ya, el PNV es, ante todo, una formación integrista desde el punto de vista religioso. Su catolicismo reaccionario no significa, sin embargo, que se subordine a los dictámenes de la jerarquía católica, a la que en más de una ocasión acusa de españolista, creando verdaderos momentos de tensión. Muchos clérigos vieron abierto el

MENDI J. G., y MÁIZ R., (comps), Los nacionalismos en la España ...op. cit., p. 275.

33. Cfr. MEES, L., "Clases, religión y Nación: el sindicalismo nacionalista en el País Vasco hasta la Guerra Civil," en DE LA CUEVA MERINO, J., Izquierda obrera y religión en España (19001939), 2012, pp. 155-178.

34. Para un análisis general de la incidencia de la Revolución de octubre del 34 en el País Vasco, puede verse FUSI AIZPURÚA, J. P., "Nacionalismo y Revolución: Octubre de 1934 en el País Vasco," en Octubre 1934: cincuenta años para la reflexión, Siglo XXI Editores, Madrid, 1985, pp. 177-198. camino de devolver a la Iglesia el poder y la influencia social perdidos por culpa del liberalismo secularizante, y abrazaron la nueva ideología nacionalista. Sobre todo, como apuntan los investigadores Aizpuru y Unanue, fueron sacerdotes de las clases más humildes y de las zonas rurales, jóvenes en su mayoría, quienes desde los altares promovieron y expandieron las nuevas ideas, llegando a constituir hasta un $30 \%$ de todo el clero vasco. ${ }^{35}$

\section{La cuestión autonómica}

Como hemos dejado apuntado más arriba, la dicotomía autonomismo/independentismo es el dilema sobre el que discurre buena parte de la acción del nacionalismo vasco. Y no se trata solo de un problema de elección, sino que también existe un problema común a ambas tendencias. La importancia simbólica que tiene el fuerismo para el primer nacionalismo vasco de inspiración aranista no sirve como fundamento normativo de la nueva comunidad que se quiere crear, sino como reivindicación de un pasado idealizado y romántico. La fragmentación entre las tres provincias vascongadas, con instituciones propias e independientes, y Navarra, hacía difícil la concreción de un proyecto común de futuro sobre el que asentar la idea de autonomía o de independencia. ¿Autonomía? ¿Independencia? Sí, pero, ¿de qué? ¿De las provincias individualmente o de todo el territorio en su conjunto?

La solución que el PNV, tomando como referencia el pensamiento de Sabino

35. AIZPURU, M., Y UNANUE, D., "El clero diocesano guipuzcoano y el nacionalismo vasco: un análisis sociológico,” en BERAMENDI J. G., Y MÁIZ R., Los nacionalismos en la España... op. cit., p. 294. 
al respecto, intentó otorgar fue la de un confederalismo vasco teñido aún de férreo provincialismo. Es decir, garantizar la autonomía de las provincias, de los territorios históricos, al tiempo que se articularan instituciones comunes en esa nueva región/Estado independiente.

Con la llegada de la República, el PNV suaviza sus posiciones y renunciando en la práctica inmediata al objetivo de la independencia, decide centrar todos sus esfuerzos en conseguir un Estatuto de autonomía para las provincias vascas dentro del régimen republicano. Estatuto que sería el primer paso hacia ese hipotético y ansiado futuro de autogobierno. Impera, por tanto, una visión pragmática y contemporizadora que, a pesar de no contentar a toda la formación, va a ser la seña de identidad del nacionalismo vasco durante los seis años de paz de la joven República Española.

\section{El Estatuto de Estella}

Como dice Corchera Atienza, "cuando se acababa de celebrar el Pacto de San Sebastián (con ausencia de nacionalistas y demás fuerzas políticas fueristas o similares) y cuando los catalanistas habían conseguido convencer a republicanos y socialistas sobre el carácter regional (luego integral) que había de tener la II República, no estaba muy avanzada la reflexión existente en el País Vasco sobre el tema autonómico."36

La República coge de sorpresa a un nacionalismo vasco sin teorización seria so-

36. CORCUERA ATIENZA, J., "Fuerismo y autonomía en el estatutismo vasco durante la II República”, en BERAMENDI J. G., y MÁIZ R., Los nacionalismos en la España ...op. cit., p. 358. bre el autonomismo, más concentrado en historicistas teorías romántico/fueristas y en no menos imaginarios escenarios de independencia "nacional." Pero, como decimos, aprovechan los nuevos aires republicanos para, desde un punto de vista puramente pragmático y posibilista, alcanzar mayores cuotas de autogobierno con la finalidad de que, así, se profundice en la construcción de la nación vasca y de la conciencia independentista.

De este modo, nada más proclamada la República, el PNV no tarda en encargar a la Sociedad de Estudios Vascos (SEV) un primer proyecto de Estatuto, que es aprobado por la junta de dicha Sociedad, con una inusitada rapidez, el 31 de mayo del 31. En verdad, este primer proyecto de Estatuto son cuatro en uno, pues la SEV dividió los trabajos entre cuatro subcomisiones de Estatuto, una por cada una de los territorios históricos más Navarra. Cada subcomisión es, además, auxiliada por las asambleas municipales provinciales, de alcaldes, que realizan propuestas y colaboran en la redacción. Se quedan así al margen las Comisiones Gestoras de las Diputaciones (instituciones provinciales), que dependían directamente del Gobierno de Madrid al ser de designación gubernamental. Al mismo tiempo, al ser los diferentes proyectos redactados por asambleas de alcaldes en pie de igualdad, el mundo rural, donde el PNV tenía más fuerza, queda sobrerrepresentado, en perjuicio de las grandes ciudades donde el PSOE o los republicanos tenían aún un peso significativo. ${ }^{37}$

El 14 de junio de 1931, dos meses después de la proclamación de la República, los distintos proyectos se llevan a la Asamblea Magna de Municipios de

37. Ibid., p. 360 . 
Estella, ${ }^{38}$ donde recibe numerosas enmiendas. Discutido punto por punto el proyecto, sería definitivamente aprobado por los 427 ayuntamientos presentes (sólo 20 ayuntamientos votaron en contra o se abstuvieron). EI PSOE, las fuerzas republicanas y ANV decidieron ausentarse, por lo que el proyecto de Estella nace ya con una importante tara de calidad democrática.

El Estatuto General del Estado Vasco, pues ese sería su nombre oficial, declara el Estado vasco autónomo dentro del Estado español, Estado vasco formado por cuatro provincias (Vizcaya, Guipúzcoa, Álava y Navarra) que recibirían el nombre común de Euzkadi.

En el proyecto de Estatuto se sigue dando gran importancia a los territorios, en una especie de confederación como la ideada por Sabino y parte del aranismo posterior a él. Las Juntas Vascongadas (provinciales) y las Cortes de Navarra son definidas como las cotitulares del poder legislativo vasco en sus respectivas competencias, mientras que el poder legislativo común reside ahora en el Consejo General del Estado Vasco, integrado por 20 representantes de cada entidad histórica (tres provincias vascas más Navarra). Un total de 80 representantes que son los que forman dicho Consejo General y los que tienen capacidad de legislar sobre las materias comunes competencia del Consejo y atribuidas por el Estatuto.

Dentro de este Consejo, 2 representantes de cada entidad, es decir, 8 en total, constituyen la Comisión Ejecutiva, que hace las veces de gobierno o poder ejecutivo. Su presidente, que lo es también del Consejo General, es elegido por mayoría absoluta de los 80 miembros de éste, por 2 años. Su

38. La reunión debía haberse celebrado en Pamplona, pero debido a diferencias de última hora con los carlistas, se decidió llevarla a Estella. cargo se renueva rotatoriamente entre los 2 representantes de cada territorio.

La sede de ambas instituciones se situaría en Vitoria, capital simbólica del nacionalismo vasco, a pesar de (o precisamente por) ser la ciudad vasca donde menos presencia tiene.

Asimismo, el Estatuto contemplaba un mecanismo de resolución de conflictos entre las instituciones comunes y las provinciales, al establecer una Comisión mixta de entendimiento entre ambas y un Tribunal Supremo del País Vasco como última instancia de decisión. Parece claro que tanto la SEV como los representantes municipales de Estella calcaron en el Estatuto el sistema institucional del propio PNV, compuesto por un Consejo Ejecutivo Nacional (EBB), integrado por un número igual de los Consejos Regionales que han sido designados por las Asambleas, un Presidente, un Tribunal "Supremo" interno, etc. ${ }^{39}$

Las referencias a la soberanía del pueblo vasco chocan, por otra parte, con la propia distribución institucional. En efecto, el poder legislativo y ejecutivo que el Estatuto establece no derivan de la "soberanía" o voluntad del pueblo vasco, sino de los representantes de las diputaciones, en un sistema de legitimidad indirecta y mediata. Y, además, se da una doble paradoja, pues dichas proclamaciones solemnes de soberanía se enfrentan con la propia inserción que el Estatuto hace en el conjunto del Estado español. El País Vasco se constituye, dice el proyecto, como un Estado miembro dentro de una República federal.

Como es fácilmente deducible, el entramado institucional que se creaba era al-

39. Un análisis de todo el Estatuto puede verse en DE LA GRANJA SAINZ, J. L., Nacionalismo y II República en el País Vasco, op. cit., pp. 144170 y $270-286$. 
tamente disfuncional y confuso, y más habida cuenta de la ausencia aún de una Constitución republicana, entonces en proceso de elaboración. Adelantar por ciencia infusa la propia configuración futura del marco constitucional que se desprendería del poder constituyente era un ejercicio cuanto menos atrevido por parte de los redactores de Estella. Y, de hecho, esta sería una de las principales causas del fracaso del proyecto.

En cuanto al sistema de distribución de competencias, el Estatuto contenía lagunas notables. A través de una doble lista establecía las competencias del Estado y las del País Vasco, de manera excesivamente rígida y sin cláusulas flexibilizadotas que permitieran su constitucionalidad. Esa vinculatoriedad al Estado central antes de la existencia misma de una Constitución republicana no tenía fundamento, y así sería denunciado posteriormente.

¿Pero acaso estas lagunas que aquí indicamos no fueron vistas por la Asamblea de Estella? Efectivamente, parece ilusorio pensar que no se dieron cuenta, ab initio, de tales disfunciones y del carácter atrevido, y hasta de predistigitación, de la totalidad del Estatuto. Ello ha hecho pensar a los investigadores e historiadores que la intención del Estatuto, rápidamente redactado, fue más la de ser bandera de la reivindicación autonómica, instrumentalizándolo políticamente como elemento de agitación panfletaria, sin más intenciones normativas.

La novedad radica, no obstante, en que, por primera vez, la restauración de los Fueros no es la primera reivindicación, al tiempo que se logra presentar un proyecto común de País Vasco, disfuncional, sí, pero común a todos los territorios históricos. ${ }^{40}$

40. CLAVERO, B., "Los fueros de las Provincias Vascas ante la autoría de la República Española”,
El punto del Estatuto que más reticencias y molestias causó en Madrid, sobre todo entre los republicanos, fue el monopolio de las instituciones vascas sobre las relaciones Iglesia-Estado, que posibilitaba la firma de un nuevo concordato con la Iglesia Católica sólo para el País Vasco. Habida cuenta de la naturaleza integrista y religiosa del nacionalismo vasco liderado por el PNV, el concordato sería aún más beneficioso para la Iglesia que el que estaba vigente en el conjunto de España. Esa regresión se veía como intolerable por parte de las fuerzas republicanas y socialistas laicas, y más tras el abierto anticlericlarismo que se desprendía del texto constitucional que estaba elaborándose. Dicha competencia exclusiva para el País Vasco fue introducida por la Asamblea Magna de Municipios en Estella, ya que no se contemplaba en los diversos proyectos enviados por la SEV. Ello nos lleva a asegurar, como destaca Estornés Zubizarreta, que la Asamblea de Estella lleva a cabo una lectura "más fundamentalista y confesional" del Estatuto, contentando así, además, a los sectores más integristas y cercanos al carlismo tradicionalista. ${ }^{41}$

\section{Un nuevo escenario}

El proyecto de Estatuto chocará enseguida, como es evidente, con la Constitución de la República española que se aprueba por las Cortes Constituyentes el 9 de diciembre de 1931.

en Revista Vasca de Administración Pública, $\mathrm{n}^{\circ}$ 15, p. 55. La única referencia a los Fueros en este proyecto se contiene en Preámbulo, con expresiones pseudomíticas e historicistas.

41. ESTORNÉS ZUBIZARRRETA, I., "El autonomismo vasco antes de 1936", en Simposium sobre el Estatuto vasco de 1936, Instituto Vasco de Administraciones Públicas, Oñate, p. 107. 
La renovación del nacionalismo español, hacia un nacionalismo de corte liberal que sitúa la concepción nacional en el plano jurídico, y no en el cultural o ideológico, permite la instauración de un Estado que respete en su seno el pluralismo territorial y los particularismos locales. El miedo (o desconocimiento) a lo federal impone un modelo de Estado "integral" novedoso, con caracteres típicamente federales pero sin llegar a tales extremos. La figura de Azaña en esa renovación del nacionalismo es esencial, como en la propia consolidación del ideal republicano. El nacionalismo español se desprende en buena parte de su afirmación férrea del centralismo estatalista, y facilita el acuerdo que permite integrar en el nuevo consenso constitucional a los republicanos catalanes. Los nacionalistas vascos, en cambio, no asumirán ab initio la nueva posibilidad que les abre la República, y el PNV no votará a favor de la Constitución. Y más cuando por Decreto de 8 de diciembre de 1931, se establece que la redacción de los futuros Estatutos de autonomía deberá respetar, necesariamente, los presupuestos y disposiciones constitucionales. En vigor ya la Constitución, la minoría vasca en las Cortes españolas retira el Estatuto de EsteIla. Con el fracaso, por todos previsto y nada traumático, del proyecto de Estatuto, el nacionalismo vasco cambia de estrategia.

Desde la proclamación de la República en abril se habían constituido, bajo control y designación directa de los Gobernadores civiles, Comisiones Gestoras que se hicieron cargo de las diputaciones provinciales vascas hasta las próximas elecciones. El PNV, partidario de un mayor municipalismo afín a sus intereses y donde estuviera sobrerrepresentado el mundo rural, rechazó en un inicio la formación de estas Gestoras, pero con el fracaso del Estatuto de Estella decide dar una oportunidad a estas instituciones, que comenzarán la redacción de un nuevo Estatuto.

Al mismo tiempo, el PNV, aliado en las Cortes de los tradicionalistas de base carlista, con quienes compartían su integrismo y conservadurismo, ve cómo se queda aislado al apoyar la investidura como Presidente de la República a Niceto Alcalá Zamora, odiado por los tradicionalistas que, en el fondo, repudiaban la República. Con el apoyo a Alcalá Zamora, parece aceptar, tácitamente, el régimen republicano y su Constitución, de ahí que los reaccionarios tradicionalistas rompan su pacto con los nacionalistas. De hecho, esto supondrá un acercamiento del PNV con los republicanos de izquierda, incluso con algunos sectores de su enemigo tradicional, el PSOE, a través de la figura de Prieto. Pero el acercamiento fue, no obstante, débil, y siguió siendo aliado de la derecha reaccionaria representada por el carlismo, y del Partido Radical de Lerroux. Esta moderación del PNV, sin embargo, en su búsqueda y consecución de una autonomía para el País Vasco, no sentará demasiado bien entre sus propias filas, y acarreará en un futuro nuevas escisiones como la de Jagi-Jagi en 1934, heredero de Aberri, que integraba el sector más radical-aranista del PNV.

\section{El proyecto de las gestoras y el comienzo de la querra}

El PNV, como vemos, apoya la redacción por parte de las Gestoras de un nuevo proyecto de Estatuto, en el que participan, de forma consultiva, los municipios vascos de las tres provincias y Navarra.

Efectivamente, en enero de 1932 se convoca una reunión entre las Comisiones 
Gestoras de las Diputaciones y los municipios que tiene por finalidad la elaboración de un Estatuto acorde, ahora sí, con la nueva Constitución de la República. El 11 de marzo de 1932, la Comisión nombrada al efecto acaba sus trabajos, siendo presentado ante todos los municipios vascos el 19 de junio del mismo año, en Pamplona. El proyecto de las Gestoras recibe el respaldo de la mayoría de ayuntamientos de Álava, Vizcaya y Guipúzcoa, pero es rechazado por los navarros con el impulso de los carlistas. Ello provoca el enfrentamiento entre los otrora tradicionales aliados carlistas y el PNV, alianza que ya no se volverá a recuperar.

El proyecto hereda del de Estella una ambigüedad disfuncional buscada intencionalmente como apertura jurídica y previa indefinición política. Parece atribuir competencia legislativa, y no meramente administrativa, a las provincias, lo cual supondría una más que dudosa constitucionalidad, ya que el monopolio sobre la creación de la ley residía o bien en las Cortes de la República, o bien en las regiones autónomas constituidas. Lo que se intenta es, pues, crear una región dentro del marco constitucional pero en la que pervivan, con especial importancia, las diversas especificidades autónomas de las provincias.

Los diputados del Parlamento autonómico serían elegidos la mitad por todo el pueblo vasco en circunscripción única, y la otra mitad, por el electorado de cada provincia, igual en número a pesar de las diferencias demográficas. El Parlamento nombraría de entre sus miembros, y por mayoría, un Presidente del Consejo Permanente, especie de poder ejecutivo integrado por consejeros con la participación de las provincias.

En cuanto a las competencias, el Estatuto no establece con claridad un listado único de reparto, sobre todo en materia fiscal. Efectivamente, en cuanto a los impuestos, parece que en un primer momento otorga la competencia a la Región, pero al mismo tiempo dice respetar el régimen de concierto provincialista. Esta indefinición hace pensar en una compatibilidad entre una hipotética Hacienda Vasca regional que puede recibir la titularidad o el ejercicio de más impuestos por parte del Estado, y la de los conciertos de las Diputaciones Forales.

Asimismo, a diferencia del de Estella, el de las Gestoras no reconoce ningún mecanismo de resolución de conflictos entre las provincias y las instituciones comunes, quedando quizá la puerta abierta a una intervención del Tribunal de Garantías Constitucionales de la República ex art.30 de su ley reguladora. ${ }^{42}$

Sea como fuere, ante el rechazo de $\mathrm{Na}$ varra el PNV decide, en consecuencia, adaptar el Estatuto a la nueva situación y circunscribirlo a las tres provincias vascas. Con el respaldo de éstas, y siendo un Estatuto completamente constitucional, nada impediría, en teoría, su promulgación y entrada en vigor. El 5 de noviembre del 32 es aprobado en referéndum por el 84\% del censo electoral, aunque con una menor participación de Álava.

Sin embargo, las elecciones legislativas de noviembre del 33 otorgan la victoria a la derecha española, comenzando así el denominado Bieno Negro. El PNV es aliado de Lerroux, el principal beneficiado de las elecciones. Incluso los nacionalistas Ilegan a respaldar su confianza en las Cortes, con el objetivo de conseguir

42. Para todo el proceso que siguió a la presentación del Estatuto de las Gestoras, puede verse DE LA GRANJA SAINZ, J. L., Nacionalismo y II República en el País Vasco, pp. 392-462. 
el tan ansiado Estatuto. En contra de las previsiones nacionalistas, sin embargo, el proyecto de las Gestoras empieza a tener visos de fracaso en las Cortes. El Partido Radical y la CEDA, argumentando la baja participación de Álava y el hecho de que no hubiera aprobado por mayoría el plebiscito a favor del Estatuto (aunque ello no era constitucional ni legalmente necesario), exigen, primero, que se separe del proceso esta provincia vasca. ${ }^{43}$ La oposición del PNV y la radicalización de Lerroux y la CEDA enfanga el proyecto hasta su total rechazo en las Cortes radical-cedistas, en medio de un clima de tensión territorial con Cataluña y social con los sectores populares. El proyecto de Estatuto cae así en el olvido, y la derecha retoma su política centralista, antiautonomista e incluso antivasca. Este rechazo al Estatuto hace que el PNV aumente sus acercamientos a la izquierda, abandonando definitivamente todo apoyo al partido radical de Lerroux. ${ }^{44}$ En busca, como decimos, de apoyos a su autonomía, establece una velada alianza con las fuerzas republicanas y de izquierdas en las Cortes, lo que provoca la escisión de Jagi-Jagi en el 34.

Se da así un extraño fenómeno: durante el bienio social-azañista, el PNV, por naturaleza, es aliado de la oposición conservadora y tradicionalista, y durante el Bieno Negro radical-cedista, se acerca en una alianza antinatura a la nueva oposición socialista y republicana. Siguiendo a Payne: "el nacionalismo vasco era demasiado conservador para la izquierda moderada

43. Cfr. SANTIAGO DE PABLO., El nacionalismo vasco en Álava (1907-1936), Bilbao, pp. 128 y ss.

44. CASTELLS, J. M., El Estatuto Vasco, Aramburu, San Sebastián, 1975; y FUSI, J. P., El problema vasco en la II República, Turner, Madrid, 1979. en 1931-1932, y demasiado liberal para la derecha moderada en los años 19341935." 45

Los acontecimientos precipitados que darán fin al Bieno Negro impedirán que florezca ningún otro proyecto de Estatuto, y que el de las Gestoras permanezca en el olvido forzado por la hegemonía de las derechas en las Cortes y en el Gobierno. Los escándalos de corrupción, el clima de tensión política, la huelga general revolucionaria, o los devaneos secesionistas de la Generalitat de Cataluña, precipitarán la convocatoria de nuevas elecciones legislativas para febrero de 1936. Las izquierdas españolas, unidas bajo el aura del Frente Popular, ganarán, aunque no sobradamente, dichas elecciones, decantando de nuevo las Cortes hacia la izquierda. El PNV, acercándose al PSOE y sobre todo, a Indalecio Prieto, comenzará una nueva aventura estatutaria. Sin embargo, el estallido de la Guerra Civil en julio del 36 avocará a la República a su división y futura desintegración.

Durante la Guerra, el Estatuto vasco por fin podrá aprobarse y entrar el vigor el 6 de octubre del 36, sin la participación de Navarra y con el apoyo de ANV, el PSOE, el PCE, Izquierda Republicana y el resto de partidos. En plena contienda, el Gobierno golpista que ya controlaba media España declarará, mediante Decreto en 1937, traidoras a las provincias de Vizcaya y Guipúzcoa. El fin de la República dará paso a más de 40 años de franquismo, donde todo atisbo siquiera de autonomía será duramente reprimido y perseguido.

45. PAYNE, S. G., El nacionalismo vasco. De sus orígenes a ETA, Dopesa, Barcelona, 1974, p. 206. 


\section{Conclusión}

El nacionalismo vasco, de profundas raíces conservadoras y tradicionalistas, comulga mal con el nuevo espíritu transformador de la República española. El secreto de su éxito, la creación del antagonismo etnocéntrico vasco/español como eje transversal e interclasista, es a la vez su mayor obstáculo para poder integrarse en un marco constitucional que, ahora sí, respeta en su seno el pluralismo territorial. El carácter laico, cuando no abiertamente anticlerical, del régimen constitucional, choca con las intenciones integristas de un nacionalismo anclado en el historicismo idílico de los Fueros y monopolizado por el partidomovimiento sui generis PNV.

El dilema autonomía/independencia parece decantarse, durante la República, a favor de la primera opción desde el pragmatismo político característico de este periodo que busca, por todos los medios posibles, la consecución de un régimen de autonomía para el País Vasco. Este objetivo implica la aceptación tácita de la legitimidad del nuevo marco constitucional y provoca, por su rechazo, escisiones dentro del PNV más aranista.

Detrás de esa meta estatuista subsiste, al menos en la teoría, otra mayor y más lejana en el tiempo de independencia total y soberanía plena. Considerado el Estatuto como un medio y la autonomía como un instrumento en aras de la creación y consolidación de una conciencia nacional, el PNV dará su beneplácito a todos los proyectos de Estatuto que se suceden en la etapa republicana, como el de Estella (marcadamente conservador, tradicionalista y confederal) o el de las Comisiones Gestoras (más integrador y adecuado a la Constitución).
Lo cierto y verdad es que, a diferencia de ERC, el nacionalismo vasco personalizado en el PNV, y a pesar de sus teóricos planteamientos soberanistas, será fiel a la República en todo momento, defendiendo incluso su legalidad y legitimidad cuando en julio del 36 se produzca el golpe de Estado que daría comienzo a la Guerra (in)Civil.

De haber seguido existiendo... ¿podría la República haber neutralizado e integrado con éxito el nacionalismo vasco? A día de hoy, no lo sabemos. Pero después de más de tres décadas en democracia, en una democracia que respeta hasta el summun el pluralismo territorial de quienes la componen, parece que los nacionalismos periféricos no se arredran, y muy al contrario, continúan en su espiral de odio hacia lo español; cuando, por ignorancia o por dolosa desidia, no comprenden que lo español es tan catalán o vasco como lo vasco o lo catalán es tan español. La creación artificial y forzosa de antagonismos constituye el sustrato principal del que se nutren los nacionalismos periféricos para su supervivencia y expansión. Nacionalismos que, como el vasco, hunden sus férreas raíces en el tradicionalismo más absurdo y en el racismo más deplorable.

El nacionalismo español de corte liberal o liberal democrático, que recoge una tradición secular impulsada y enriquecida por grandes nombres de nuestra cultura, no ha sabido renacer de las cenizas del franquismo. El olvido de esa tradición liberal y democrática que ha defendido la idea de España (y que la defendió a lo largo de la República), por parte de una izquierda acomplejada por la patrimonialización que hizo la Dictadura de los símbolos nacionales, y de una derecha poco dada a ejercicios de historiografía, trae como consecuencia la impunidad dialéctica 
de unos nacionalismos periféricos basados en la insolidaridad y la acentuación de las diferencias. Recuperar las figuras, entre tantos otros, de Pi i Margall, Zorrilla, Canalejas, Sagasta, Castelar, Ortega, Alcalá-Zamora y, cómo no, de Azaña, como partes de una tradición nacional rica e integradora, se convierte en la actualidad en un ejercicio insoslayable de quienes defendemos, y así lo creemos, la convivencia común de todos los españoles en un régimen de derechos y libertades.

Se preguntaba el historiador intergaláctico de la metáfora de Hobswan por qué el nacionalismo era tan importante en los últimos siglos. Y la respuesta, lejos de estar acabada, parece no dejar de perfilarse. Pero lo que sí está claro es que el nacionalismo ha acompañado la construcción del Estado moderno desde los albores de la Revolución francesa, enriqueciendo y consolidando los Estados, al tiempo que parte de sus ideas, enraizadas en concepciones culturales e historicistas, han desolado buena parte del mapa europeo. Si la Historia nos enseña algo es a no volver a cometer los mismos errores de nuestros antecesores, y es evidente que uno de los más crasos errores, de las más grandes ignominias de la Humanidad, ha venido dado por la creación de enemigos artificiales bajo criterios nacionalistas, por encima de los derechos de las personas y de los pueblos. Impedir que vuelvan siquiera a atisbarse las causas que los provocaron es nuestra tarea.

\section{Bibliografía}

AZAÑA, M., La velada de Benicarló, Edit. Castalia, Madrid, 1974.

AZAÑA, M., Obras completas, Edit. Oasis, México, 1966.
AIZPURU, M., Y UNANUE, D., "El clero diocesano guipuzcoano y el nacionalismo vasco: un análisis sociológico," en BERAMENDI J. G., Y MÁIZ R. (Comps.), Los nacionalismos en la España la II República, Siglo XXI Editores, Madrid, 1991.

BERAMENDI J. G., Y MÁlZ R. (Comps.), Los nacionalismos en la España la II República, Siglo XXI Editores, Madrid, 1991.

CASTELL, L., Modernización y dinámica política en la sociedad guipuzcoana de la Restauración, 1876-1915, Siglo XXI, Madrid, 1987.

CASTELLS, J. M., El Estatuto Vasco, Aramburu, San Sebastián, 1975.

CLAVERO, B., "Los fueros de las Provincias Vascas ante la autoría de la República Española", en Revista Vasca de Administración Pública, no 15.

CORCUERA ATIENZA, J., "Perspectiva del nacionalismo vasco. Integración y asimilación", en Revista Internacional de Sociología, enero-marco de 1983, nº 45.

CORCUERA ATIENZA, J., "Fuerismo y autonomía en el estatutismo vasco durante la II República", en BERAMENDI J. G., y MÁIZ R. (Comps.), Los nacionalismos en la España de la I/ República, Op. cit, pp. 357-376.

CORCUERA ATIENZA J., Orígenes, ideología y organización del nacionalismo vasco (1876-1904), Siglo XXI, Madrid, 1979.

DE BLAS GUERRERO, A., Tradición republicana y nacionalismo español, Tecnos, Madrid, 1991.

DE LA GRANJA SAINZ, J. L., Nacionalismo y II República en el País Vasco, Siglo XXI, Madrid, 2008.

DE LA GRANJA SAINZ, J. L., "El antimaketismo: la visión de Sabino Arana sobre España y los españoles," en Norba. Revista de Historia, nº 19, 2006, pp. 191-203.

DE PABLO, S., "Notas sobre la base social del nacionalismo vasco (1931-1936), en 
BERAMENDI J. G., y MÁlZ R. (Comps.), Los nacionalismos en la España de la II República, Op. cit., pp. 275-286.

ELORZA, A., Ideologías del nacionalismo vasco. 1876-1937, Aramburu, San Sebastián, 1978.

ESTORNÉS ZUBIZARRETA, I., "El autonomismo vasco antes de 1936", en Simposium sobre el Estatuto vasco de 1936, Instituto Vasco de Administraciones Públicas, Oñate.

FUSI AIZPURÚA, J. P., El problema vasco en la I/ República, Turner, Madrid, 1979.

FUSI AIZPURÚA, J. P., "Nacionalismo y Revolución: Octubre de 1934 en el País Vasco," en Octubre 1934: cincuenta años para la reflexión, Siglo XXI Editores, Madrid, 1985, pp. 177-198.

FERNÁNDEZ SEBASTIÁN, J., "Antecedentes: fuerismo, carlismo y nacioalismo", en Los nacionalistas: historia del nacionalismo vasco, 1876-1969, 1995, pp. 17-51.

GELLNER, E., Naciones y nacionalismo, Alianza Universidad, Madrid, 2001.

HERNÁNDEZ MARCO, J. L., (Coord.), La industrialización del norte de España, Universidad del País Vasco, 1988.

HOBSBAWN, E., Naciones y nacionalismo desde 1780, Ed. Crítica, Barcelona, 1995. JÁUREGUI GURUTZ, "Bases sociales en el nacionalismo vasco durante la II República", en BERAMENDI J. G., y MÁIZ R. (Comps.), Los nacionalismos en la España, Op. cit., pp. 239-254.

KORTAZAR URIARTE, J., "La literatura vasca y la creación de la Nación: ideas de José Aristimuño, "Aitzol" (1896-1936)", en ROMERO TOBAR, L., (Coord.), Literatura y nación: la emergencia de las literaturas nacionales, 2008, pp. 207-222.

LARRONDE J. C., El nacionalismo vasco: su origen y su ideología en la obra de Sabino Arana-Goiri, Txertoa, San Sebastián, 1977.
MEES, L., "Clases, religión y Nación: el sindicalismo nacionalista en el País Vasco hasta la Guerra Civil," en DE LA CUEVA MERINO, J., Izquierda obrera y religión en España (1900-1939), 2012, pp. 155-178. MOLAS, I., "Los nacionalismos durante la II República. Una perspectiva comparada", en BERAMENDI, J. G., y MÁIZ, R. (Comps.), Los nacionalismos en la España de la /l República, Op. cit., pp. 13-26.

MORIN E., Pensar Europa. La metamorfosis de un continente, Gedisa, Barcelona, 2003.

ORTEGA Y GASSET, J., Obras completas, Alianza-Revista de Occidente, Madrid, 1983, vol. VI.

PAYNE, S. G., El nacionalismo vasco. De sus orígenes a ETA, Dopesa, Barcelona, 1974.

QUIROGA FERNÁNDEZ DE SOTO, A., "Hermanos de sangre. Regenaracionismo, catolicismo y racismo en los nacionalismos españoles, catalanes y vascos (1890-1945)," en Joaquín Costa y la modernización de España, marzo, 2011

RAMOS LARRIBRA, C., "El nacionalismo vasco durante la dictadura de Primo de Rivera", en Letras de Deusto, vol. 15, $n^{\circ}$ 31, 1985.

SANTIAGO DE PABLO., El nacionalismo vasco en Álava (1907-1936), Bilbao, pp. 128 y ss.

SOLOZABAL, J. J., El primer nacionalismo vasco, Tucar, Madrid, 1975.

TOMÁS Y VALIENTE, Francisco, Obras completas, Centro de Estudios Políticos y Constitucionales (en adelante CEPC), Madrid, 1997, tomo III, p. 2.587.

TORRES VILLANUEVA, E., Ramón de la Sota: 1857-1936: un empresario vasco, LID, Madrid, 1998. 